\title{
Uma leitura crítica do momento político e a importância da revista como espaço de reflexão
}

Desirée Guichard Freire, Floriano Godinho de Oliveira, Guilherme Ribeiro e Leandro Dias de Oliveira

\section{Q OpenEdition \\ 1 Journals}

\section{Edição electrónica}

URL: http://journals.openedition.org/espacoeconomia/5174

DOI: 10.4000/espacoeconomia.5174

ISSN: 2317-7837

Editora

Núcleo de Pesquisa Espaço \& Economia

\section{Refêrencia eletrónica}

Desirée Guichard Freire, Floriano Godinho de Oliveira, Guilherme Ribeiro e Leandro Dias de Oliveira, "Uma leitura crítica do momento político e a importância da revista como espaço de reflexão », Espaço e Economia [Online], 13 | 2018, posto online no dia 17 dezembro 2018, consultado o 23 setembro 2020. URL : http://journals.openedition.org/espacoeconomia/5174 ; DOI : https://doi.org/ 10.4000/espacoeconomia.5174

Este documento foi criado de forma automática no dia 23 setembro 2020.

(C) NUPEE 


\title{
Uma leitura crítica do momento político e a importância da revista como espaço de reflexão
}

\author{
Desirée Guichard Freire, Floriano Godinho de Oliveira, Guilherme Ribeiro e \\ Leandro Dias de Oliveira
}

1 A Revista Espaço e Economia apresenta mais uma edição fazendo uma homenagem em sua capa à lembrança de um massacre ocorrido em novembro de 1988, na cidade de Volta Redonda, RJ, em que três operários perderam suas vidas, no mesmo ano em que se promulgava a atual Constituição brasileira, tida como Constituição Cidadã, promulgada em 05 de outubro de 1988. Não bastou uma constituição cidadã, pois as forças da repressão continuaram agindo com violência contra a vida.

2 Em 2018, após a realização de eleições presidenciais pautadas pela defesa da violência, por parte do candidato eleito, contra as minorias etnicas e raciais; contra as manifestações e lutas de gênero e liberdade sexual; pela criminalização dos movimentos social que defendem as causas indígenas, culturais, de moradia, da terra para plantar e inúmeros ativismos sociais etc, dois lideres dos sem-terra são executados por homens encapuzados na cidade de Alhandra, no interior do estado da Paraíba.

Uma constituinte dita cidadã, uma eleição dita democrática não são, portanto, garantias de respeito à vida e à democracia. Neste sentido, a partir do cenário de incertezas e violências em que o Brasil entra nesse quadrante temporal da imposição do projeto neoliberal que domina o país, o debate acadêmico, a produção científica, a reflexão sobre a produção da riqueza e sua justa distribuição, a investigação sobre a super exploração do trabalho, o desvelamento das estratégias de transferências de valor para os fundos de investimentos e capitais globalizados, a reflexão sobre as políticas territoriais e o pacto federativo, o aprofundamento teórico acerca das políticas públicas e do planejamento econômico territorial, entre outros inúmeros temas, se constituem desafios que precisam ser enfrentados.

4 Isso porque as mudanças nas estruturas economias e políticas vivenciadas no mundo influem nos fundamentos e nas estratégias da organização econômica e nas relações de 
trabalho, atingindo particularmente (de forma aguda e profunda) o território, em face da forte dependência de investimentos públicos para fomentar seu dinamismo.

5 Com efeito, no Brasil, a recente mudança do poder político e a imposição de práticas neoliberais, baseado em projeto alçado ao poder de forma não legítima, produz uma regressão significativa das mudanças que estavam em curso. 0 discurso hegemônico é contraditório com as ações, pois a coalizão que está no poder não está sendo capaz de reverter a crise econômica em que mergulharam o país, apesar das inúmeras e aceleradas transformações nos fundamentos das bases econômicas e sociais, com ações deletérias no que diz respeito aos gastos públicos e direitos trabalhistas. Assim, estamos diante de um novo quadro político, econômico e social, que já repercute na organização territorial no país.

6 Assim, a Revista Espaço e Economia, como um canal de disseminação da produção acadêmica do campo instituído pela Geografia Econômica e pela Economia Regional, buscará aprofundar e aperfeiçoar sua linha editorial propondo para o próximo ano debates entorno do tema "transformações no capitalismo mundial e a produção social do espaço: novos arranjos territoriais e a economia política do desenvolvimento", que será objeto do III Colóquio Espaço e Economia, organizado pelos pesquisadores dos núcleos de pesquisas que dirigem a revista. Com essa proposta procuraremos destacar as contribuições críticas que desvelem as contradições e conflitos observados nas ações instituídas pelo governo neoliberal que se avizinha e os efeitos econômicos, sociais e territoriais decorrentes dessas políticas.

7 Neste número que ora apresentamos, queremos destacar a riqueza dos temas e artigos publicados e as novas seções que passarão a compor a estrutura da revista. Além dos artigos que apresentam investigações avançadas e/ou concluídas e a seção "trilha de pesquisa", que mostram trabalhos em desenvolvimento, passaremos a publicar a seção "Dossiês" que agregarão textos apresentados em fóruns ou eventos e/ou que tenham sido especialmente elaborados para tratar de temas específicos. Publicaremos também a seção "Conexões", com o intuito de divulgar trabalhos publicados em outras revistas, livros eletrônicos ou sites de interesses, publicando um pequeno resumo e link para o acesso direto do trabalho.

8 Nesta edição, abriremos com um artigo que muito nos alegrou e que motivou a capa, pois se trata de uma defesa da vida, uma defesa de uma economia para a vida, enfatizando o que o autor, Prof. Dr. Luis Alvares Lozano, da UNAM, destacou como os quatro momentos da atividade econômica, quais sejam, a produção, a distribuição, a troca e o consumo da riqueza. Na sequência, merece atenção a apresentação realizada por Roberto Santos sobre a obra teórica do filósofo checo Radovan Richta, em que devela um profícuo debate de Richta com alguns críticos marxistas e não-marxistas sobre as contradições entre as forças produtivas e as relações de produção no capitalismo contemporâneo.

9 Outro artigo que queremos destacar - Análise da crise do Subprime e os derivativos de créditos nos EUA - enfatiza as origens da derrocada da economia americana por estratégias de grupos financeiros, que acabaram por produzir a derrocada de milhares de pessoas, deixando-as sem emprego e sem moradia.

10 Os dois artigos que se seguem destacam, cada um deles, processos fundamentais na compreensão das desigualdades sociais no Brasil, pois o primeiro, de Hiran e Isa Martins, enfoca o tema educação nos marcos do projeto neoliberal no Brasil e, no caso do artigo de Pedro Guimarães, uma abordagem inovadora no campo da Teoria Marxista 
da Dependência sobre a descriminação e segregação na incorporação dos trabalhadores afrodescendente, oriundos do período escravocrata no final do século XIX, mostrando uma das origens da segregação racial ainda vigente no Brasil.

11 O debate sobre os serviços e equipamentos urbanos é trabalhado nos artigos seguintes, iniciando-se por uma caracterização importante sobre o que André Gonçalves denominou obsolescência espacial urbana, no qual enfatiza aspectos da teoria da localização e da renda fundiária urbana para caracteriza o que denomina de degradação em ambientes urbanos. Este trabalho é seguido por textos de Nelson Mabucanhene, do Instituto de Superior de Administração Pública de Mabuto, Moçambique, que destaca a ineficiencia da política de transporte na capital do país; de Felipe Ramão que analisa as transformações urbanas causadas pelos investimentos em turismo na cidade de Cabo Frio e o artigo de Alison e Amanda Nascimento, destacando as mudanças delineadas pela instalação de uma grande indústria no entorno da cidade de Imperatriz, no estado do Maranhão.

12 Fechando a seção dos artigos, temos nesta edição o texto produzido coletivamente por economistas da Universidade Regional do Cariri, estado do Ceará, realizando uma importante análise sobre a atividade pecuarista e a exportação de carne bovina no Brasil.

13 Nesta edição trazemos ainda o Dossiê - Processos e mudanças espaciais na Hungria. Nele, publicamos quatro artigos de colegas húngaros que apresentam temas diversificados que envolvem a economia e aspectos do desenvolvimento regional na Hungria e/ou envolvendo a Hungria, como na integração na União Europeia.

o primeiro artigo, dos autores Ákos Jakobi, Brigitta Zsom e Zsófia Vida analisa o uso das tecnologias de informação e de comunicação como inseparável de várias esferas da vida cotidiana, destacando que esse fenômeno pode estar relacionado com uma perceptível influência sobre as desigualdades sócioeconômicas - as quais, necessariamente, admitem reflexos geográficos. No estudo se busca apreender o fenômeno tendo em conta que embora as diferentes camadas das desigualdades reflitam outras razões das disparidades na Era da Informação na Hungria, as desigualdades urbano-rural e centroperiferia são feições comuns à estrutura espacial.

15 O segundo artigo analisa o desemprego estrutural na Hungria, a partir das taxas regionais de desemprego, destacando a qualificação da força de trabalho como um possível indicador de desequilíbrio. 0 estudo destaca a relação de entre empregos de profissionais de nível superior e a influência desta demanda para a geração de empregos menos qualificados. Para os autores há forte relação entre esses dois níveis de qualificação, sendo que, estimativas próprias sobre taxas de desemprego referentes a qualificações específicas mostram que um aumento na percentagem de possuidores de diplomas de nível superior diminui a taxa de desemprego dos trabalhadores com qualificação mais baixa.

16 A intergração com a União Europeia é tratada no artigo de Máté Farkas e Pál Szabó, e destacam que a desigualdades regionais na União Européia tem aumentado tanto em termos políticos quanto econômicos. Para os autores, a incorporação de novos membros em 2004 desvelou a existência de fortes disparidades regionais, o que exige estudos e políticas importantes para a superação das desigualdades.

17 Por fim, em um trabalho mais dedicado a cidade de Budapeste, Péter Baji, Márton Berki e Éva Izsák realizam uma revisão teórica sobre a cidade como fenômeno urbano e 
analisam as mudanças no centro histórico e econômico, decorrentes do desenvolvimento de uma nova estrutura econômica. Para os autores há uma forte relação entre a nova economia e as mudanças no centro, bem como na áreas próximas das áreas historicas da cidade.

Desejamos boa leitura e bom proveito dos trabalhos aqui apresentados.

19 Os editores 